\title{
Clinical Efficacy Of Ceftriaxone Versus Ciprofloxacin In Paediatric Enteric Fever
}

\author{
Anila Farhat, Asma Shaukat, Tariq Mahmood Khan
}

ABSTRACT:

Objective: Determination of the clinical effectiveness of ciprofloxacin versus ceftriaxone in children with enteric fever on the basis of defervescence within 72 hours of commencement of treatment.

Duration and Place of Study: This randomized controlled trial was carried out from $15^{\text {th }}$ May to $15^{\text {th }}$ November 2017 in pediatrics units of Benazir Bhutto Shaheed Teaching Hospital Abbottabad and Jinnah International Hospital Abbottabad.

Methodology: 90 children with uncomplicated enteric fever were admitted and divided randomly into two groups, Group A was administered I/V Ceftriaxone $75 \mathrm{mg} / \mathrm{kg}$ OD and Group B was given I/V Ciprofloxacin $10 \mathrm{mg} / \mathrm{kg}$ BD for seven days. Response to drug was taken as defervescence within 72 hours while continued fever after 72 hours was taken as no response. The data was analyzed by using SPSS Version 21.00 .

Results: In our research study 53(58.9\%) children were male and 37(41.1\%) patients were female. The mean age was $8.43 \pm 3.17$ years encompassing 4 to 14 years, mean weight of the patients in $\mathrm{kg}$ was $29.54 \pm 10.8 \mathrm{~kg}$. Efficacy of ceftriaxone group was $93.3 \%$ while in ciprofloxacin group $62.2 \%$ patients became afebrile in 72 hours. The proportion of achieving defervescence within 72 hours was higher with ceftriaxone than with ciprofloxacin

Conclusion: Ceftriaxone is more efficacious in terms of achieving defervescence than ciprofloxacin in children having enteric fever.

Keywords: Clinical Efficacy, Ceftriaxone, Ciprofloxacin, Enteric Fever in Children, Defervescence

\section{- - - - - - - - - - - - -} INTRODUCTION

Enteric fever is an infectious disease caused by Salmonella enterica Typhi and Salmonella enterica Paratyphi A, B and C. There may be milder to serious manifestations of disease which usually starts six to thirty days after introduction of causative agent. It is a common cause of morbidity in developing countries where a higher burden of disease is borne by children. The incidence rate varies from 180494/100,000 among 5-15 year-olds and 140-573/100,000 among 2-4 years olds.

There are different forms in which a patient can present. One form is confirmed enteric fever in which patient has a body temperature $=38^{\circ} \mathrm{C}\left(100.6^{\circ} \mathrm{F}\right)$ for at least three days with a positive culture of $S$. typhi. Second form is presumable typhoid fever in which temperature is $=38^{\circ} \mathrm{C}$ for at least three days, with a positive serodetection without $S$. typhi isolation. Other persons are protracted carriers who pass $S$.

I Anila Farhat

I Assistant Professor, Paediatric Department, Frontier Medical | I and Dental College, Abbottabad

I Asma Shaukat

Associate Professor Pharmacology, Department of

I Pharmacology and Therapeutics, Women Medical and Dental I

I College, Abbottabad.

I E mail: a_shaukat11@yahoo.com

I Tariq Mahmood Khan

Assistant Professor, Department of Pharmacology and Therapeutics, Frontier Medical and Dental College, Abbottabad I

Received: 06-05-2018

Revised: 26-05-2018

I Accepted: 05-06-2018

1

느-- - - - - - - - - - - - - - typhi in faeces or urine for longer than a year after an episode of acute typhoid fever ${ }^{1}$. Humans are the only natural host and reservoir of this bacteria. Food and water soiled with infected person's excreta serves as contagion of disease. The greatest proportion of people get the disease due to supply of sewage contaminated water. Ice creams have been identified as one of significant risk in the development of disease $^{2}$.

The patient usually presents with fever, a coated tongue, diarrhea, vomiting, headache, constipation and abdominal pain $^{3,4}$. In the endemic areas diagnosis is often made clinically due to non-availability of laboratory facilities for blood culture definitive for specific diagnosis of typhoid fever ${ }^{4,5}$. Complications in children can involve multiple organs like in adults. These include gastrointestinal complications (bleeding and perforation, hepatitis, cholecystitis and abscesses of liver and spleen), central nervous system complications which include seizures, encephalopathy and brain abscess while bronchopneumonia can ensue as a respiratory tract complication ${ }^{6}$.

Both injectable and oral vaccines for prevention of enteric fever are available ${ }^{3}$. First line drugs include chloramphenicol, ampicillin and co-trimoxazole while second line drugs include quinolones like ciprofloxacin for the management of typhoid fever ${ }^{1}$. With emergence of drug resistant strains of Salmonella spp. in various countries including Pakistan, the response to these drugs is seen to be reduced and now the empiric treatment relies on third generation cephalosporins like ceftriaxone ${ }^{2,4,5,7}$. However their employment is restrained for cases who show resistance to traditional drugs as well as flouroquinolones. Resistance to flouroquinolones was 
not reported till late nineties, however since last decade flouroquinolones resistant cases of enteric fever have been observed $^{8}$.

So keeping in view emerging drug resistance in population the current study is aimed at comparing the clinical effectiveness of ciprofloxacin and ceftriaxone with regard to patient's response to therapy with either.

\section{METHODOLOGY:}

This randomized controlled trial research was performed for a duration of six months that is from $15^{\text {th }}$ May to $15^{\text {th }}$ November 2017 in Pediatric ward of Benazir Bhutto Shaheed Teaching Hospital and Jinnah International Hospital Abbottabad. Consecutive sampling technique was applied for this study. Ninety children of either sex, aged between 4-14 years having enteric fever diagnosed on the basis of clinical presentation and positive typhidot test (IgM antibodies) were admitted and enrolled in the study. While exclusion criteria included known hypersensitivity to quinolones or lactam antibiotics, presence of complications, history of use of oral or intravenous antibiotics in last seven days as well as absence of fever at the time of enrollment. Informed consent was obtained from the parents of the children verbally as well as by documentation. Information about clinical presentation, laboratory typhidot test and treatment was recorded on detailed proformas. The Hospital Ethical committee gave prior approval for the study.

Two groups of forty five children in each were randomly formed in equal ratio based on random numbers. Group A patients were given injectable ceftriaxone $75 \mathrm{mg} / \mathrm{kg}$ IV OD for 7 days ${ }^{9}$ while patients of group B received ciprofloxacin $10 \mathrm{mg} / \mathrm{kg}$ IV/BD for 7 days ${ }^{10}$. During the hospital stay typhidot test was done in the hospital laboratory under supervision of pathologist. Both groups were regularly observed for response to therapy. Response was described in our study as achievement of defervescence within 72 hours and no response was labeled when there was no abatement of fever in 72 hours.

\section{STATISTICAL ANALYSES}

Analysis of data was done using SPSS version 21.00. For age mean and standard deviation were determined while gender frequency and defevescence in 72 hours were determined using percentages. Chi square test was used to determine efficacy of two groups.

\section{RESULTS}

A total of 90 patients with 45 patients in each group were included in the study. In our research study, mean age of the patients was $8.43 \pm 3.17$ ranging from 4 to 14 years, mean weight of the patients was $29.54 \pm 10.8$ ranging from 10 to $54 \mathrm{~kg}$ as shown in figure 1 . Out of the total 90 patients $53(58.9 \%)$ were male children while thirty seven, that is $41.1 \%$ were females. Frequencies of patients stratified in three age groups: $12(13.3 \%)$ children were below 5 years of age, 52(57.8\%) patients were between 5-10 years while $26(28.9 \%)$ patients were above 10 years. It was found that only $25.6 \%$ (23 out of 90 ) of patients were using boiled water in routine while remaining $74.4 \%$ (67 out of 90) of patients were having tap or well water as shown in table 1.

Clinical presentation of children with enteric fever is shown in table 2. Most of the patients presented with fever. Eight patients had fever $<100^{\circ} \mathrm{F}$, sixty children had fever between 100 to $103^{\circ} \mathrm{F}$ while twenty two patients had high grade fever of $>103^{\circ} \mathrm{F}$. Only twenty six patients were irritable while rest had clear sensorium. In 86 patients, that is $95.6 \%$ liver was not palpable while $4(4.4 \%)$ patients were found to have palpable liver $<2.5 \mathrm{~cm} .31$ patients presented with diarrhea while nausea and vomiting along with fever was presenting complaint in thirty and forty patients respectively. Patients found with diffuse abdominal pain were 52(57.8\%) while $1(1.1 \%)$ child had pain localized in right hypochondrium as shown in table 2.

Out of total 53 male patients $23(25.6 \%)$ received ciprofloxacin and $30(33.3 \%)$ received ceftriaxone while out of total 37 female patients $22(24.4 \%)$ received ciprofloxacin and $15(16.7 \%)$ were given ceftriaxone as shown in table 3 .

The number of patients in both groups that is Group A (Ceftriaxone I/V) and Group B (Ciprofloxacin I/V) achieving defervescence within 72 hours were observed and their percentages were calculated. It was found that in ceftriaxone group A 42(93.3\%) patients achieved the response while three patients remained febrile even after 72 hours of treatment. In the ciprofloxacin (Group B) 28(62.2\%) patients showed positive response while $17(18.9 \%)$ children gave no response in 72 hours as shown in table 3 .

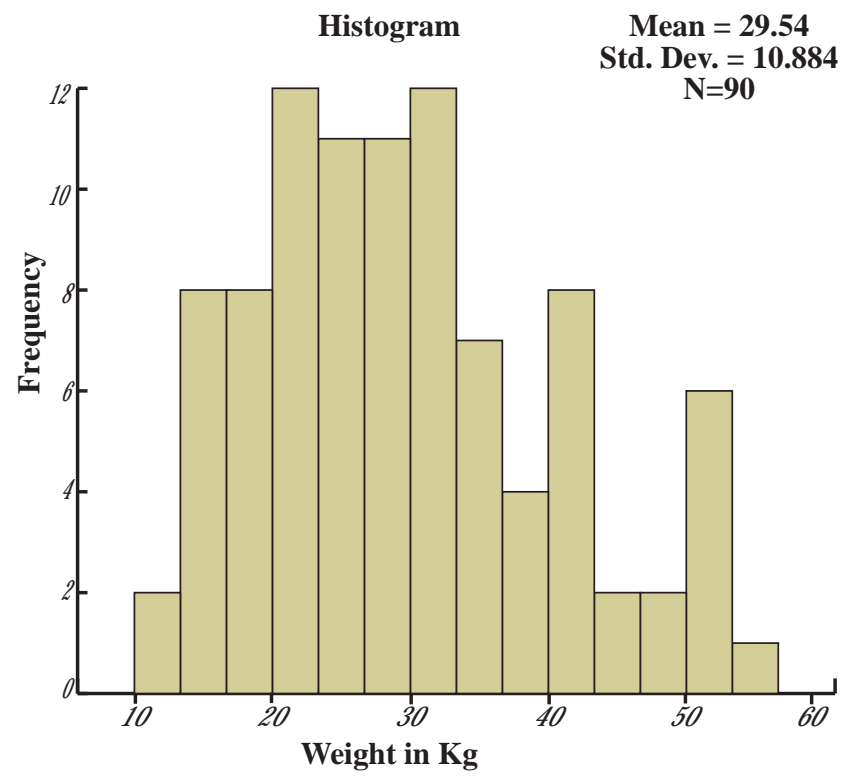

Figure 1: Histogram of weight in $\mathrm{kg}(\mathrm{n}=90)$ 
Anila Farhat, Asma Shaukat, Tariq Mahmood Khan

\begin{tabular}{|l|c|c|}
\hline \multicolumn{1}{|c|}{ Variables } & No of Patients $(\mathrm{n}=90)$ & Percentage $(\%)$ \\
\hline GENDER: & & \\
Male & 53 & 58.9 \\
Female & 37 & 41.1 \\
\hline AGE: & 12 & \\
< 5 years & 52 & 13.3 \\
5 to 10 years & 26 & 28.9 \\
Above 10 years & & \\
\hline Use of Boiled water & 23 & 25.6 \\
Yes & 67 & 74.4 \\
No & & \\
\hline
\end{tabular}

Table 1: Frequency of gender, age based distribution and use of boiled water:

\begin{tabular}{|c|c|c|c|}
\hline Fever & $\begin{array}{l}\quad \mathbf{1 0 0 . 6}^{\mathbf{0}} \mathbf{F} \\
8(7.2 \%)\end{array}$ & $\begin{array}{l}\mathbf{1 0 0 . 6} \text { to } \mathbf{1 0 3}^{\circ} \mathbf{F} \\
60(54.0 \%)\end{array}$ & $\begin{array}{r}>\mathbf{1 0 3}^{\mathbf{o}} \mathbf{F} \\
22(19.8 \%)\end{array}$ \\
\hline Mental status & $\begin{array}{l}\text { Clear } \\
64(71.1 \%)\end{array}$ & $\begin{array}{l}\text { Irritable } \\
26(28.9 \%)\end{array}$ & $\begin{array}{l}\text { Coma/Delirium } \\
0(0 \%)\end{array}$ \\
\hline Liver Size & $\begin{array}{l}\text { Not palpable } \\
86(95.6 \%)\end{array}$ & $\begin{array}{l}<2.5 \mathrm{~cm} \\
4(4.4 \%)\end{array}$ & $\begin{array}{l}>2.5 \mathrm{~cm} \\
0(0 \%)\end{array}$ \\
\hline Loose motion & $\begin{array}{l}\text { None } \\
59(65.6 \%)\end{array}$ & $\begin{array}{l}\text { Mild } \\
30(33.3 \%)\end{array}$ & $\begin{array}{l}\text { Severe } \\
1(1.1 \%)\end{array}$ \\
\hline Vomiting & $\begin{array}{l}\text { None } \\
19(21.1 \%)\end{array}$ & $\begin{array}{l}\text { Nausea } \\
30(33.3 \%)\end{array}$ & $\begin{array}{l}\text { Vomiting } \\
41(45.6 \%)\end{array}$ \\
\hline Abdominal pain & $\begin{array}{l}\text { None } \\
37(41.1 \%)\end{array}$ & $\begin{array}{l}\text { Diffuse } \\
52(57.8 \%)\end{array}$ & $\begin{array}{l}\text { RHC } \\
1(1.1 \%)\end{array}$ \\
\hline Result of Abdominal exam & $\begin{array}{l}\text { None } \\
83(92.2 \%)\end{array}$ & $\begin{array}{l}\text { Distention } \\
7(7.8 \%)\end{array}$ & $\begin{array}{l}\text { Ileus/peritonitis } \\
0(0 \%)\end{array}$ \\
\hline
\end{tabular}

Table 2: Clinical Presentation of enteric fever in children:

\begin{tabular}{|l|c|c|c|}
\hline Response & $\begin{array}{c}\text { Ceftriaxone } \\
\text { A. N=45 }\end{array}$ & $\begin{array}{c}\text { Ciprofloxacin } \\
\text { B. N=45 }\end{array}$ & $\begin{array}{c}\text { Total } \\
\text { N=90 }\end{array}$ \\
\hline Male Patients & $30(33.3 \%)$ & $23(25.6 \%)$ & $53(58.9 \%)$ \\
\hline Female Patients & $15(16.7 \%)$ & $22(24.4 \%)$ & $37(41.1 \%)$ \\
\hline Defervescence within 72 hours: & $\begin{array}{c}42 \\
(93.3 \%)\end{array}$ & $\begin{array}{c}28 \\
(62.2 \%)\end{array}$ & $\begin{array}{c}70 \\
(77.8 \%)\end{array}$ \\
\hline Febrile after 72 hours: & $\begin{array}{c}17 \\
(6 \%)\end{array}$ & $\begin{array}{c}20 \\
(37.7 \%)\end{array}$ \\
\hline
\end{tabular}

Table 3: Frequency of children showing defervescence within 72 hours:

\section{DISCUSSION:}

Enteric fever is one of the most prevalent virulent diseases representing $4^{\text {th }}$ most common cause of mortality in Pakistan with the greatest occurrence in children between 5-19 years of age ${ }^{11}$ which according to WHO criteria is considered to be high $^{12}$. So disease poses a significant public health issue. With the emergence of resistance of S.typhi to multiple drugs treatment of enteric fever has become more difficult and complications are more likely to emerge especially in children. So due to resistance to traditional drugs like 


\begin{tabular}{|l|c|c|c|c|c|}
\hline & & df & $\begin{array}{c}\text { Asym. Sig. } \\
\text { (2 sided) }\end{array}$ & $\begin{array}{l}\text { Exact Sig. } \\
\text { (2 sided) }\end{array}$ & $\begin{array}{c}\text { Exact Sig. } \\
\text { (1-sided) }\end{array}$ \\
\hline Pearson Chi-Square & 18.021 (b) & 1 & .000 & & \\
\hline $\begin{array}{l}\text { Continuity } \\
\text { Correction (a) }\end{array}$ & 16.751 & 1 & .000 & & \\
\hline $\begin{array}{l}\text { Likelihood Radio } \\
\text { Fisher's Exact Test }\end{array}$ & 22.115 & 1 & .000 & .000 & .000 \\
\hline N of Valid Cases & 90 & & & & \\
\hline
\end{tabular}

Table 4: Chi Square Test for Comparison

chloramphenicol, ampicillin etc, Ciprofloxacin has been promoted as preferred agent for typhoid fever in children in our setups. However studies have shown that resistance to Ciprofloxacin is emerging ${ }^{8,13}$. It has been reported that ceftriaxone may be more effective in regions where enteric fever is endemic with high levels of resistance ${ }^{13-14}$.

So our research was aimed to determine the effectiveness with regard to achieving defervescence in 72 hours of intravenous ceftriaxone $75 \mathrm{mg} / \mathrm{kg}$ OD against Ciprofloxacin $10 \mathrm{mg} / \mathrm{kg}$ BD in children with enteric fever. A total of 90 patients randomized in two groups of 45 patients in each (Group A: Ceftriaxone and Group B: Ciprofloxacin) were included. In our research study, mean age of the patients was $8.43 \pm 3.17$ ranging from 4 to 14 years, mean weight of the patients was $29.54 \pm 10.8$ ranging from 10 to $54 \mathrm{~kg}$. Out of 90 patients 12 patients (13.3\%) were below 5 years of age with maximum number of children $(52$, i.e. $57 \%$ ) in 510 years of age. This is in accordance with the studies wherein overall disease occurrence was lowest in $<5$ years and highest prevalence was seen in 5-9 years age group while 26 children (28.9\%) were above 10 years of age ${ }^{15,16}$. Male patients were found to be 53(58.9\%) and females were $37(41.1 \%)$ in this study. Our findings are also similar to a study conducted in Holy Family Hospital Rawalpindi which included 88 patients $41(46.6 \%)$ children were male, the mean age and weight being $8.3 \pm 1.94$ years and 24.7 $\pm 6.3 \mathrm{~kg}$ respectively ${ }^{10}$.

In our research study fever was present in all patients with 82 patients having temperature more than $100 \mathrm{~F}$. Other common associated complaints were diffuse abdominal pain in $57.8 \%$ of patients and vomiting in $45.6 \%$ of children. In a study conducted in Faridpur, Bangladesh fever was the presenting symptom in all the patients followed by vomiting and diarrhea in $18 \%$ of children. Abdominal pain was present in only $10 \%$ of patients. ${ }^{17}$ Likewise in another study pyrexia was present in all individuals followed by emesis and abdominal pain in $31 \%$ patients, findings are somewhat similar to our study ${ }^{18}$.

Out of total 90 patients 70 patients that is $77.8 \%$ became afebrile in 72 hours while 20 patients $(22.2 \%)$ remained febrile even after the said time period. In ceftriaxone group A 42 out of 45 patients (93.3\%) achieved defervescence in 72 hours and only three patients (6\%) showed no response. While in group B that is Ciprofloxacin group 28 out of 45 children $(62.2 \%)$ became afebrile and 17 children $(37.7 \%)$ remained febrile even after 72 hours. So in the present study Ceftriaxone achieved defervescence in greater number of patients and showed low failure rate than those treated with Ciprofloxacin. Our findings are therefore similar to a study conducted in Rawalpindi in which among ciprofloxacin treated children, 25 (56.8\%) showed defervescence and in 19 patients $(43.1 \%)$ fever did not subside in 96 hours while $43(97.7 \%)$ patients treated with ceftriaxone had their fever subsided in 96 hours and 1 (2.3\%) patient did not respond. So it was demonstrated in the above study that the percentage of children achieving defervescence within 96 hours was greater in the ceftriaxone treated children as compared to the those who were administered ciprofloxacin ${ }^{10}$. Another study by Butt $\mathrm{T}$ et al reported similar results ${ }^{19}$.

Our results differ from another study conducted in Thailand in which the oral Ciprofloxacin and injectable Ceftriaxone were compared to determine the time both the drugs take to lower fever to normal body temperatue in patients suffering from enteric fever. It was concluded in the study that there was no significant difference between the two methods of treatment that were employed $(\mathrm{p}<.05)^{20}$. In a meta-analyses and one another study findings it was concluded that there was no significant difference between efficacy of fluoroquinolones and cephalosporins in children with enteric fever ${ }^{21,22}$. In other studies ciprofloxacin and other fluoroquinolones was found to be superior to ceftriaxone in terms of fever clearance time and less clinical failures ${ }^{23-25}$.

\section{CONCLUSION:}

Ceftriaxone is more efficacious in terms of achieving defervescence as compared to ciprofloxacin in pediatric patients with enteric fever. This study therefore adds to the data of management of children of KPK particularly of Abbottabad suffering from typhid fever where such study 
has not been conducted previously. These findings may allow paediatricians in selecting appropriate medication for enteric fever in similar settings thereby avoiding the inconvenience of prolong treatment.

\section{LIMITATIONS}

There are however shortcomings of this study. Fever clearance time may not be adequate measure of efficacy since fever takes its own course, fever producing cytokines may continue to be produced even after clearance of $S$ typhi so some people may not achieve defervescence in the required time frame. Also this study was conducted on a smaller population which may not reflect the larger population. So large, well designed rigorous trials should be conducted to establish the efficacy of ceftriaxone in enteric fever in chidren with more confidence.

\section{CONFLICT OF INTEREST}

There is no conflict of interest of authors.

\section{REFERENCES:}

1. Background document: The diagnosis, treatment and prevention of typhoid fever. Communicable Disease Surveillance and Response Vaccines and Biologicals. World Health Organization. Cited 2015. Available from: http://www.who. int/rpc/TFGuideWHO.pdf

2. Ochiai RL, Acosta CJ, Danovaro-Holliday MC, Baiqing D, Bhattacharya SK, Agtini MD et al. A study of typhoid fever in five Asian countries: disease burden and implications for controls. Bull World Health Organ. 2008; 86(4): 260-8.

3. Zhou K, Sauve LJ, Richardson SE, Ford-Jones EL, Morris SK. Enteric Fever in a Multicultural Canadian Tertiary Care Pediatric Setting: A 28-Year Review. J Pediatric Infect Dis Soc. 2017; 6(1): 98-101

4. Azmatullah A, Qamar FN, Thaver D, Zaidi AKM, Bhutta ZA. Systematic review of the global epidemiology, clinical and laboratory profile of enteric fever. J Glob Health. 2015; 5(2): 020407. doi: 10.7189/jogh.05.020407.

5. Steele AD, Burgess DCH, Diaz Z, Carey ME, Zaidi AKM. Challenges and Opportunities for Typhoid Fever Control: A Call for Coordinated Action. Clinical Infectious Diseases. 2016; 62(s1): S4-S8.

6. Britto C, Pollard AJ, Voysey M, Blohmke CJ. An Appraisal of the Clinical Features of Pediatric Enteric Fever: Systematic Review and Meta-analysis of the Age-Stratified Disease Occurrence. Clinical Infectious Diseases. 2017; 64(11): 160411 .

7. Wain J, Hendriksen RS, Mikoleit ML, Keddy KH, Ochiai RL. Typhoid fever. Lancet. 2015; 385(9973): 1136-45

8. Mandal S, Mandal MD, Pal NK. Antibiotic resistance of Salmonella enterica serovar Paratyphi A in India: Emerging and reemerging problem. Journal of postgraduate medicine. 2006; 52(3): 163

9. Nair BT, Simalti AK, Sharma S. Study comparing ceftriaxone with azithromycin for the treatment of uncomplicated typhoid fever in children of India. Ann Trop Med Public Health 2017; 10: $205-10$

10. Naveed A, Ahmed Z. Treatment of Typhoid Fever in Children: Comparison of Efficacy of Ciprofloxacin with Ceftriaxone. European Scientific Journal. 2016; 12(6): 346-355. doi: 10.19044/esj.2016.v12n6p346

11. Khan MI, Soofi SB, Ochiai RL, Khan MJ, Sahito SM, Habib MA, et al. Epidemiology, clinical presentation and patterns of drug resistance of Salmonella Typhi in Karachi, Pakistan. The Journal of Infection in Developing Countries. 2012; 6(10): 704-14.

12. Crump JA, Luby SP, Mintz ED. The global burden of typhoid fever. Bulletin of World Health Organization. 2004; 82(5): 346-53

13. Parry CM. Treatment of multidrug-resistant and nalidixic acid-resistant typhoid fever in VietNam. Transactions of the Royal Society of Troical Medicine and Hygiene 2004; 98(7): 413-422

14. Cooke FJ, Day M, Wain J, Ward LR, Threlfall EJ. Cases of typhoid fever imported into England, Scotland and Wales. Transactions of Royal Society of Tropical Medicine and Hygiene. 2007; 101(4): 398-404

15. Karkey A, Arjyal A, Anders KL,et al. The burden and characteristic of enteric fever at a healthcare facility in a densely populated area of Khatmandu. Plos One. 2010; 5: e13988.

16. Kelly DF, Thorson S, Maskey M, et al. The burden of vaccine preventable invasive bacterial infections and pneumonia in children admitted to hospital in urban Nepal. Int J Infect Dis. 2011; 15: e17-23

17. Saha AK, Hassan MK, Kundu LC, Saha SK, Begum P. Study of the clinical profile and antibiotic response in typhoid fever at faridpur medical college hospital. Faridpur Med.Coll.J. 2017; 12(1): 02-04

18. Shah G, Ghimire A, Shrestha S. Clinical profile of culture proven enteric fever in children at university teaching hospital, Nepal. Journal of Patan Academy of Health Sciences. 2014; 1(2): 42-45

19. Butt T, Ahmad RN, Salman M and Kazmi SY. Changing trends in drug resistance among typhoid salmonellae in Rawalpindi, Pakistan. East Mediterr Health J. 2005; 11: 103844

20. Limpitikul W, Singchungchai P. Costs and Effectiveness of Ciprofloxacin and Ceftriaxone in Treatment of Typhoid Fever in Children in Thailand. International Journal of Public Health Research 2013; 1(3): 192-7

21. Thaver D, Zaidi AKM and Bhutta ZA. A comparison of fluoroquinolones versus other antibiotics for treating enteric fever: meta analyses. BMJ. 2009; 338: b1865. doi: https://doi. org/10.1136/bmj.b1865

22. Jeeyani HN, Prajapati BS, Bloch A. Enteric fever in children - Clinical profile, sensitivity patterns and response to antimicrobials. GCSMC J Med Sci. 2015; 4(1): 40-43

23. Wallace MR, Yousif AA, Mahroos GA, et al. Ciprofloxacin versus ceftriaxone in the treatment of multiresistant typhoid fever. Eur J Clin Microbiol Infect Dis.1993; 12: 907-10

24. Smith MD, Duong NM, Hoa NT et al.Comparison of ofloxacin and ceftriaxone for short course treatment of enteric fever.Antimicrob Agents Chemother. 1994; 38(8): 1716-20

25. Ganesh R, Janakiraman L, Thiruvengadam V, Sathiyasekeren M. Profile of typhoid fever in children from a tertiary care hospital in Chennai - South India. Indian J Paediatrics. 2010; 77: 1089-92 